\title{
Powder Injection Molding of Ceria-Stabilized, Zirconia- Toughened Mullite Parts for UAV Engine Components
}

\author{
RENEE MARTIN, ${ }^{1}$ MICHAEL VICK, ${ }^{2}$ RAVI K. ENNETI, ${ }^{3,4}$ \\ and SUNDAR V. ATRE ${ }^{1}$ \\ 1.-Oregon State University, 204 Rogers Hall, Corvallis, OR 97331, USA. 2.-Naval Research \\ Laboratory, 4555 Overlook Ave SW, Washington, DC 20375, USA. 3.-Global Tungsten and \\ Powders Corp, 1 Hawes Street, Towanda, PA 18848, USA. 4.-e-mail: ravi.enneti@globaltungsten. \\ com
}

\begin{abstract}
Powder injection molding (PIM) of ceria-stabilized, zirconia-toughened mullite composites were investigated in the present article with the goal of obtaining performance enhancement in complex geometries for energy and transportation applications. A powder-polymer mixture (feedstock) was developed and characterized to determine its suitability for fabricating complex components using the PIM process. Test specimens were injection molded and subsequently debound and sintered. The sintered properties indicated suitable properties for engine component applications used in unmanned aerial vehicles (UAVs). The measured feedstock properties were used in computer simulations to assess the mold-filling behavior for a miniature turbine stator. The results from the measurements of rheological and thermal properties of the feedstock combined with the sintered properties of the ceria-stabilized, zirconia-toughened mullite strongly indicate the potential for enhancing the performance of complex geometries used in demanding operating conditions in UAV engines.
\end{abstract}

\section{INTRODUCTION}

Significant research efforts are being focused currently on developing material systems and manufacturing processes to produce enhanced performance parts made from ceramics. The properties of ceramics such as light weight, high temperature stability, high creep resistance, low thermal coefficient of expansion, chemical stability, and high strength at elevated temperatures make them strong candidates for applications such as miniature engine components for unmanned aviation vehicles and portable power generation. The use of ceramic parts made for these applications will enable a higher operating temperature resulting in enhanced performance and efficiency. For example, an increase in efficiency of greater than $10 \%$ has been previously reported by coating various engine components with ceramics. ${ }^{1-3}$ However, the requirement of complex-shaped, precision parts for these applications is a major barrier in taking advantage of enhanced properties provided by ceramics. The high hardness of the ceramics makes machining the complex parts difficult and expensive, thus, minimizing the available manufacturing options to produce the parts economically. ${ }^{4-8}$ Powder injection molding (PIM), as a result of its ability and proven record of manufacturing net shape complex parts economically, is identified as a suitable choice to produce complex ceramic parts.

Over the past few decades, PIM has experienced significant growth as a result of its inherent ability to manufacture large volumes of near net shape complex parts economically. ${ }^{9-12}$ These unique characteristics of PIM resulted in the practice of the technology in manufacturing parts with complex shape and enhanced property requirements in widespread applications such as automotive, defense, electronic, medical, etc. In PIM, the shaping of the parts is carried out with an injection molding machine using a mixture of ceramic/metal powders and polymers (binder). After shaping, the polymer is removed and the part is heated to a high temperature under a controlled atmosphere to obtain the desired microstructure and properties.

The success of using PIM to manufacture complex parts with enhanced properties strongly depends on 
the ability to develop optimized powder-binder (feedstock) compositions. The use of optimized feedstocks as starting materials will enable successful processing and producing defect-free parts with enhanced properties that are required for the intended critical applications. ${ }^{4-7}$ The emphasis on feedstock properties becomes more important as a result of the complex shape of the parts that require good flow of the materials during the mold-filling phase of PIM.

Our prior publication discussed the ability of PIM to manufacture complex shape engine components for transportation from silicon nitride. ${ }^{1}$ The measured feedstock properties were used to simulate the flow of the material during injection molding. The areas susceptible for formation of defects were also identified during the simulations. Owing to their relatively lower cost and sintering temperature, it is anticipated that ceria-stabilized, zirconiatoughened mullite composites could have a decided advantage over silicon nitride in fabricating complex-shaped enhanced property parts for ceramic engine applications in unmanned aviation vehicles. ${ }^{13-16}$ Compared with mullite, zirconia-toughened mullite composites also show increased fracture toughness and creep resistance.

In this article, the use of PIM to manufacture complex-shaped parts with enhanced properties from zirconia-toughened mullite composite is presented. A new zirconia-toughened mullite feedstock was developed, and its properties were used to simulate the injection molding behavior of miniature turbine engine stators. The simulation results will assist in eliminating expensive and time-consuming trial-and-error practices currently prevalent in the PIM by selecting, developing, and optimizing various material and process parameters. The study confirmed the potential ability of PIM to manufacture complex-shaped parts requiring enhanced properties.

\section{EXPERIMENTAL}

Commercially available high-purity mullite (average particle diameter: $0.7 \mu \mathrm{m}$, and BET surface area $8.5 \mathrm{~m}^{2} / \mathrm{g}$ ) and ceria-stabilized zirconia (average particle diameter: $0.75 \mu \mathrm{m}$, and BET surface area $12.5 \mathrm{~m}^{2} / \mathrm{g}$ ) were used in the present study. Ceria was added to stabilize the high-temperature tetragonal or cubic phases of zironcia at room temperature. The scanning electron microscope (SEM) images of the as-received powders are shown in Fig. 1. A mixture of paraffin wax, polypropylene, linear low-density polyethylene, and stearic acid were used for the binder. The multicomponent system has a density of $0.873 \mathrm{~g} / \mathrm{cm}^{3}$. The two powders were mixed using an 80/20 vol.\% mullite-to-ceria stabilized zirconia ratio via wet ball milling for $24 \mathrm{~h}$ in DI water, ammonia, and a dispersant (Darvan 821A, R.T. Vanderbilt Company, Inc.). Ceria-stabilized zirconia media were used. After milling, the
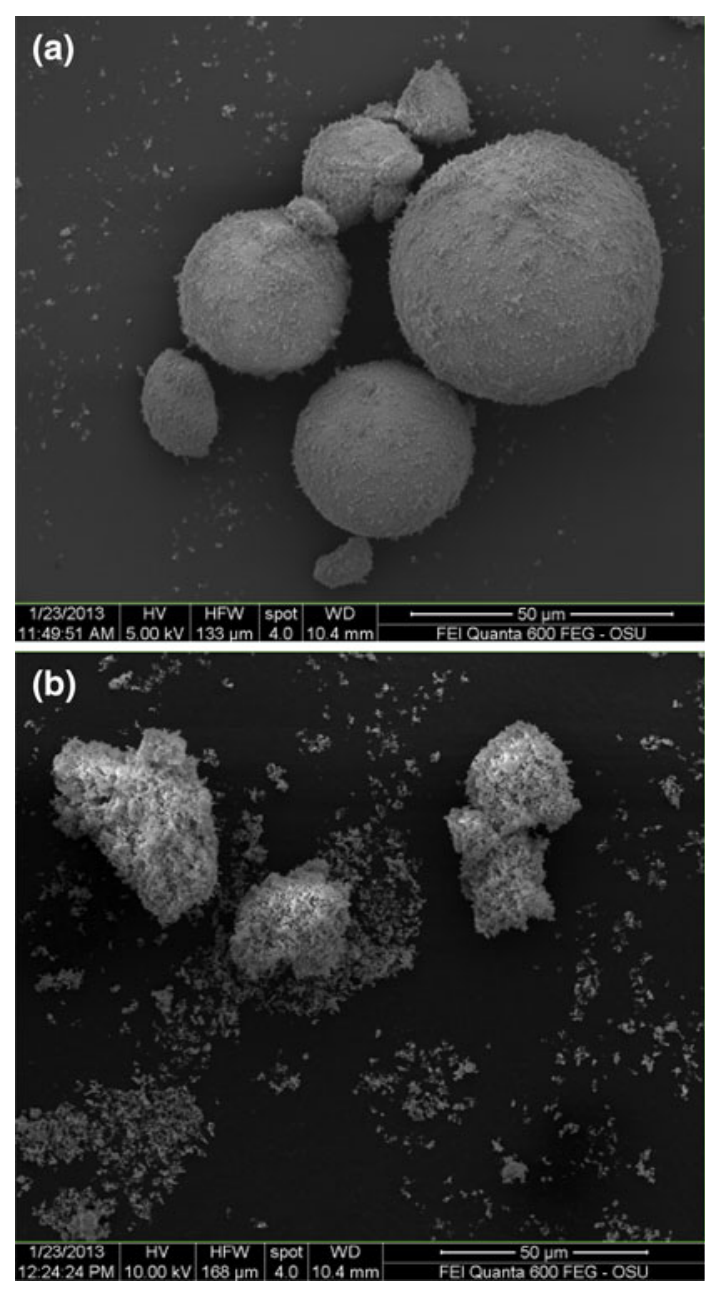

Fig. 1. Scanning electron micrographs of as-received (agglomerated) powders: (top) mullite and ceria-stabilized zirconia (bottom).

mixture was dried and heated to $550^{\circ} \mathrm{C}$ for dispersant removal. The resulting powder cake was ground and passed through a 45-mesh sieve. Feedstock compounding was carried out using an Entek co-rotating twin-screw extruder with an L/D ratio of 40 at $\sim 85$ wt.\% solids loading. Rectangular coupons, of average dimensions $38 \mathrm{~mm} \times 25 \mathrm{~mm} \times 2 \mathrm{~mm}$, were injection molded with six $\sim 1$-mm-wide slots. Molding was carried out on an Arburg $221 \mathrm{M}$ molding machine. Samples were thermally debound and sintered at $1500^{\circ} \mathrm{C}$ for $4 \mathrm{~h}$ in a production furnace at Kyocera.

Simultaneous TGA/DSC was performed on feedstock pellets using a TA Instruments SDT Q600. Samples were run in nitrogen and clean, dry air $(100 \mathrm{~mL} / \mathrm{min})$ from $30^{\circ} \mathrm{C}$ to $600^{\circ} \mathrm{C}$ at $10^{\circ} \mathrm{C} / \mathrm{min}$. Feedstock viscosity was measured by capillary rheometry (Rheograph 2003, Goettfert) in accordance with ASTM D3835. Tests were run between $150^{\circ} \mathrm{C}$ and $180^{\circ} \mathrm{C}$ at shear rates of $1 \mathrm{~s}^{-1}-10^{6} \mathrm{~s}^{-1}$. Thermal conductivity was measured using the transient linesource technique in accordance with ASTM D5930. Measurements were performed on a K-system II 
thermal conductivity from $190^{\circ} \mathrm{C}$ to $30^{\circ} \mathrm{C}$. A DSC (DSC7, Perkin Elmer) was used to determine the specific heat of the feedstock. Tests were performed in a nitrogen atmosphere $(25 \mathrm{~mL} / \mathrm{min})$ from $190^{\circ} \mathrm{C}$ to $20^{\circ} \mathrm{C}$ with a cooling rate of $20^{\circ} \mathrm{C} / \mathrm{min}$. Volume change with temperature and pressure was studied through high-pressure dilatometry with a Gnomix PVT apparatus. The tests utilized the injectionmolded parts, and the samples were heated at $3^{\circ} \mathrm{C} / \mathrm{min}$ to $200^{\circ} \mathrm{C}$. Sintered samples were polished to $0.1 \mu \mathrm{m}$ and thermally etched at $1450^{\circ} \mathrm{C}$ for $5 \mathrm{~h}$. The microstructure of the sintered parts was investigated using SEM. Vickers hardness was measured in accordance with ATSM C1327, and fracture toughness was measured via Vickers indentation. ${ }^{17,18}$ The simulations of the injection molding process were carried out using Moldflow software (Autodesk Inc.).

\section{RESULTS AND DISCUSSION}

The TGA result of the feedstock in air and nitrogen atmospheres is shown in Fig. 2. The onset for burnout of the binders starts at approximately $180^{\circ} \mathrm{C}$ in both nitrogen and air. A higher rate of binder burnout is observed in air compared with nitrogen at temperatures above $250^{\circ} \mathrm{C}$. Most of the binder (about 90 wt.\%) is removed by $400^{\circ} \mathrm{C}$ in air. Inspection of the corresponding derivative curves showed an exothermic peak in air at $290^{\circ} \mathrm{C}$ that is absent in nitrogen. The release of heat during this combustion reaction speeds the degradation of the binder components in air.

Two distinct regimes, exhibiting the burnout of the low- $\left(180^{\circ} \mathrm{C}-400^{\circ} \mathrm{C}\right)$ and high-molecular-weight components $\left(400^{\circ} \mathrm{C}-550^{\circ} \mathrm{C}\right)$ of the binder system are observed in the TGA curves under nitrogen atmosphere. These regions are not as distinct in air. The heat released from combustion, as discussed earlier, allows the high-molecular-weight components to begin to burn off at lower temperatures and blurs the separation between the two types of binder

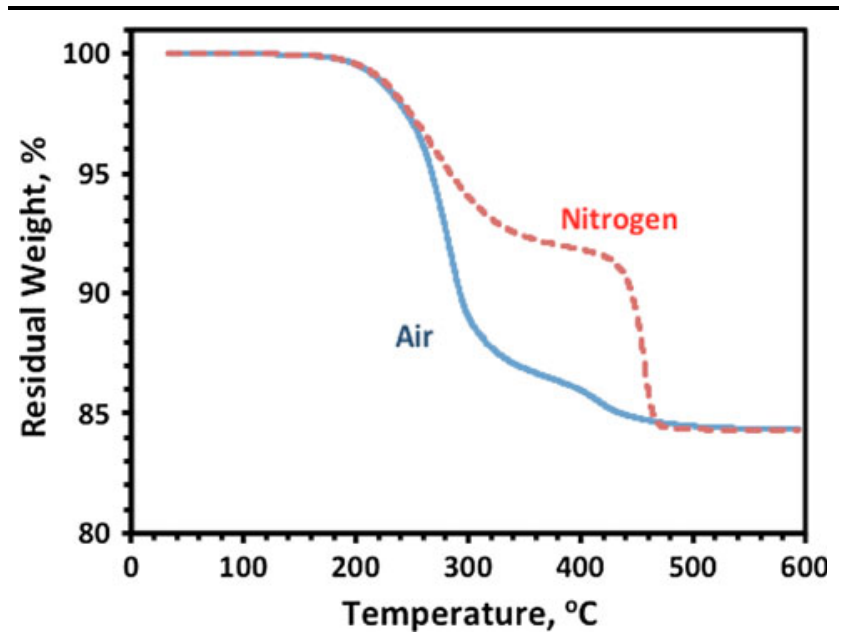

Fig. 2. TGA results of the feedstock in air and nitrogen. constituents. The observed breakdown behavior of the feedstock is used to construct the debinding schedule for thermal debinding of molded components. Both atmospheres can be used to completely thermally debind the material, although organic removal is completed at lower temperatures in nitrogen $\left(\sim 500^{\circ} \mathrm{C}\right)$ than in air $\left(\sim 550^{\circ} \mathrm{C}\right)$. A slower heating schedule in air is required to prevent defects resulting from rapid burnout between $250^{\circ} \mathrm{C}$ and $300^{\circ} \mathrm{C}$.

The rheological behavior of the feedstock is shown in Fig. 3. The viscosity of the feedstock decreases with an increasing shear rate, demonstrating the pseudoplastic flow of the feedstock. This shear thinning behavior is a required property for successful injection molding. A feedstock that exhibits dilatant, or shear thickening, behavior will experience powder agglomeration and subsequent powderbinder separation during the molding process. ${ }^{19,20}$ Furthermore, shear-thinning behavior has been shown to ease molding and reduce the occurrence of jetting. ${ }^{20}$ Viscosities also fall within the moldable

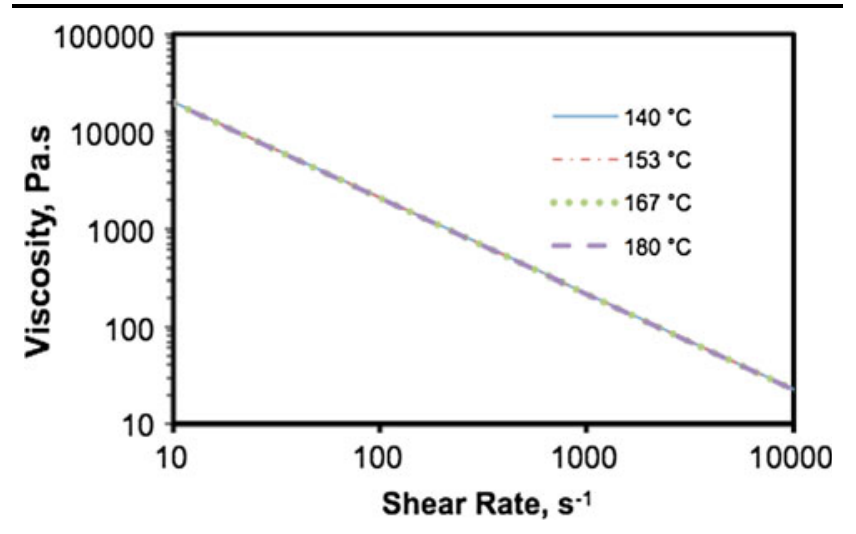

Fig. 3. Variation of viscosity of feedstock with shear rates at different temperatures.

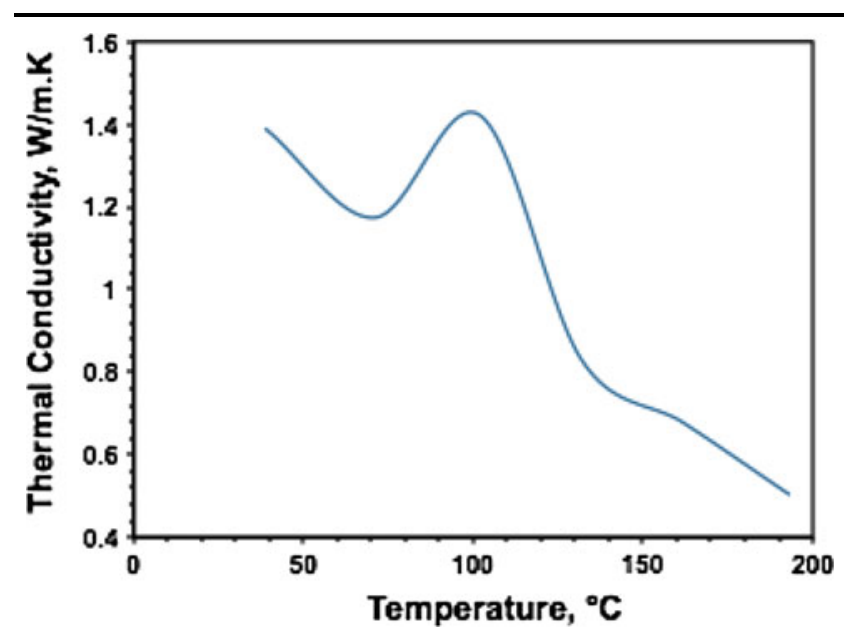

Fig. 4. Variation of thermal conductivity of feedstock with temperature. 
range (less than $10^{3} \mathrm{~Pa}$ s) for the shear rates typically experienced during molding $\left(10^{2} \mathrm{~s}^{-1}-10^{5} \mathrm{~s}^{-1}\right)$, indicating processibility over the entire melt temperature range. ${ }^{20,21}$ Furthermore, the feedstock viscosity is comparable with that of other ceramic feedstocks based on a wax-polymer binder system. For example, for a shear rate of $1000 \mathrm{~s}^{-1}$ at $160^{\circ} \mathrm{C}$, the viscosity of the zirconia-toughened mullite

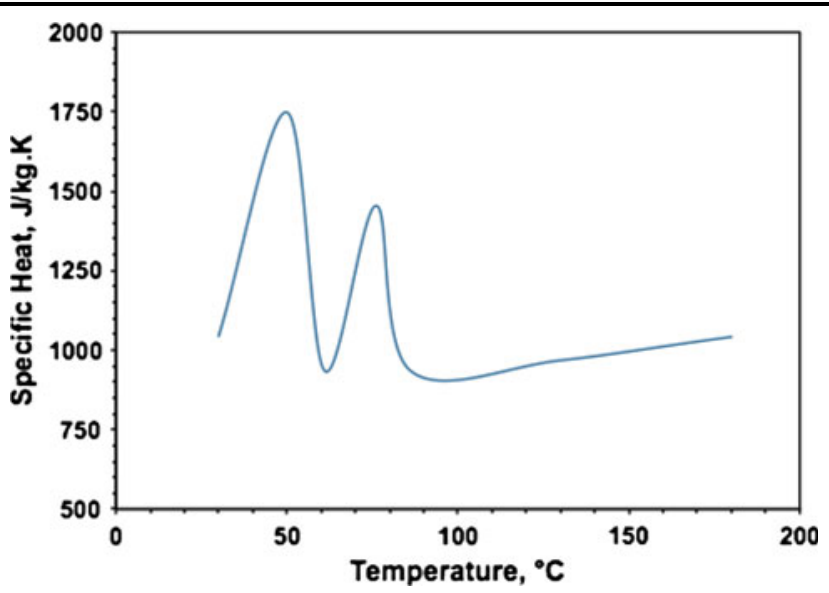

Fig. 5. Variation of specific heat of feedstock with temperature.

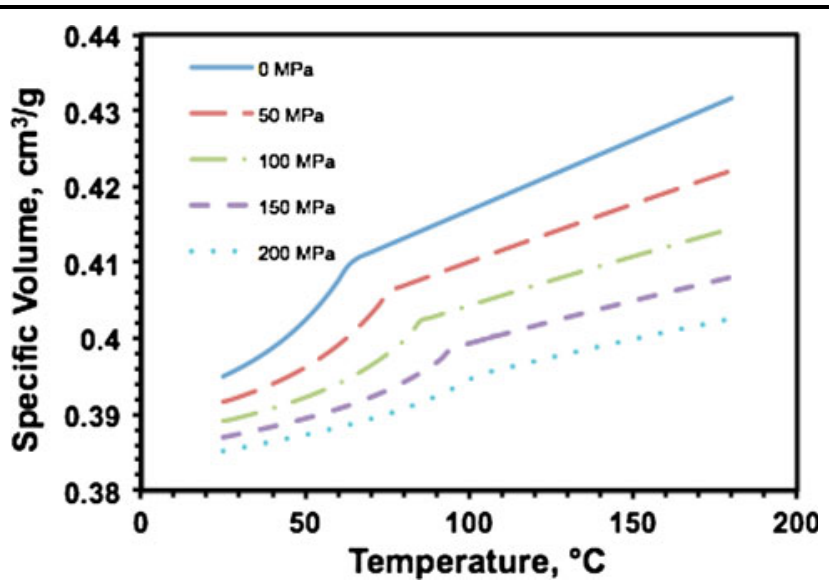

Fig. 6. Variation of specific volume of feedstock with temperature. feedstock is $\sim 230 \mathrm{~Pa}$ s. This value falls within the range reported for silicon carbide and aluminum nitride feedstocks $(\sim 100 \mathrm{~Pa} \mathrm{~s}-500 \mathrm{~Pa} \mathrm{~s}){ }^{22}$ The differences in viscosity values can be attributed to the variations in particle characteristics.

The variation of thermal conductivity of the feedstock with temperature is shown in Fig. 4. The largest increase occurs between $132^{\circ} \mathrm{C}$ and $102^{\circ} \mathrm{C}$, which corresponds to the onset of crystallization. ${ }^{23}$ Other ceramic feedstocks showed similar behavior. A strong increase in the thermal conductivity has been observed between $125^{\circ} \mathrm{C}$ and $64^{\circ} \mathrm{C}$ for an alumina feedstock and between $184^{\circ} \mathrm{C}$ and $154^{\circ} \mathrm{C}$ for a silicon nitride feedstock. ${ }^{1,24}$

The variation in specific heat of the feedstock with temperature is shown in Fig. 5. Peaks in the data mark crystallization temperatures, and lower values indicate regions of faster cooling. ${ }^{17}$ Specific heat is used along with thermal conductivity to determine the cooling behavior of the feedstock melt (i.e., flow front temperature, cooling time, etc.). ${ }^{18}$ The results for the zirconia-toughened mullite feedstock are in qualitative agreement with other ceramic feedstocks. The peak in specific heat observed in the zirconia-toughened mullite feedstock at $50^{\circ} \mathrm{C}$ is analogous to the peaks observed at $46^{\circ} \mathrm{C}$ and $49^{\circ} \mathrm{C}$ for silicon carbide and aluminum nitride feedstocks, respectively. $^{22}$

Figure 6 shows the pressure-volume-temperature (PVT) data for the zirconia-toughened mullite feedstock material. The sharp change observed in each curve marks the melting temperature at the given pressure and clearly separates the melt and solid domains. Melting temperatures are influenced by pressure and increase from approximately $64^{\circ} \mathrm{C}$ to $103^{\circ} \mathrm{C}$ as pressure increases from $0 \mathrm{MPa}$ to $200 \mathrm{MPa}$. Volume does increases with temperature, but temperature has less of an effect on volume change as the pressure is increased. Information on the PVT behavior is used during the packing phase of the injection molding process to determine the amount of additional material to be added to ensure complete mold filling as the melt begins to cool and shrink.

Table I. Representative properties of various ceramic feedstocks based on a wax-polymer binder system

\begin{tabular}{|c|c|c|c|c|c|c|c|}
\hline Reference & $\begin{array}{c}\text { Material } \\
\text { system }\end{array}$ & $\begin{array}{c}\text { Filler } \\
\text { content } \\
(\text { wt.\%) }\end{array}$ & $\begin{array}{l}\text { Initial solid } \\
\text { density } \\
\left(\mathbf{k g} / \mathbf{m}^{\mathbf{3}}\right)\end{array}$ & $\begin{array}{c}\text { Melt } \\
\text { density } \\
\left(\mathbf{k g} / \mathbf{m}^{3}\right)\end{array}$ & $\begin{array}{c}\text { Melt } \\
\text { specific } \\
\text { heat }(J / k g \cdot K)\end{array}$ & $\begin{array}{l}\text { Melt thermal } \\
\text { conductivity } \\
\quad(\mathrm{W} / \mathrm{m} \mathrm{K})\end{array}$ & $\begin{array}{c}\text { Transition } \\
\text { temperature } \\
\left({ }^{\circ} \mathbf{C}\right)\end{array}$ \\
\hline This work & Zirconia-mullite & 84 & 2520 & 2290 & 1040 & 0.7 & 81 \\
\hline 24 & Alumina & 84 & 2580 & 2340 & 1300 & 1.4 & 52 \\
\hline 21 & Aluminum nitride & 80.5 & - & 1940 & 1200 & 2.2 & 53 \\
\hline 21 & Aluminum nitride & 85 & - & 2140 & 1410 & 2.9 & 53 \\
\hline 1 & Silicon nitride & 80 & 2300 & 2110 & 1160 & 1.3 & 53 \\
\hline 21 & Silicon carbide & 89.5 & - & 1950 & 1200 & 2.5 & 52 \\
\hline 21 & Silicon carbide & 82 & - & 1990 & 1250 & 2.3 & 52 \\
\hline 21 & Wax-polymer binder & 0 & 870 & 710 & 2590 & 0.2 & 99 \\
\hline
\end{tabular}




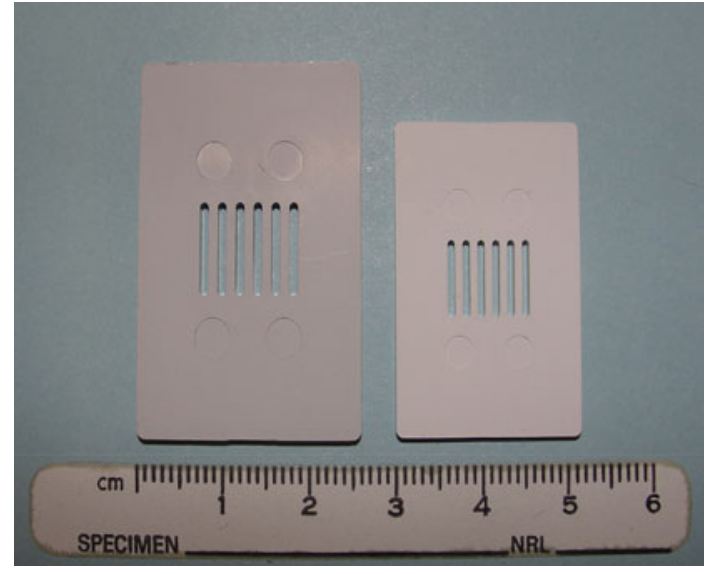

Fig. 7. Molded (left) and sintered (right) multislotted test coupon. The sample was sintered at $1500^{\circ} \mathrm{C}$ for $4 \mathrm{~h}$ to obtain a sintered density of $97.3 \%$ theoretical. A linear shrinkage of $16.5 \%$ was observed from the green to sintered stage.

Table II. Summary of the sintered properties of zirconia-toughened mullite

\section{Property}

Density, $\left(\mathrm{g} / \mathrm{cm}^{3}\right)$

3.76

Final density, \% theoretical

97.3

Linear shrinkage, (\%)

Vickers hardness, (GPa)

16.5

$K_{\mathrm{c}},\left(\mathrm{MPa} \mathrm{m}^{1 / 2}\right)$

$11.8 \pm 0.4$

$4.3 \pm 0.3$
Table I shows some representative properties of various ceramic feedstocks based on a wax-polymer binder system.

The binder system properties are also given for comparison. The sensitivity of feedstock behavior to the material system (i.e., filler material) can be determined from an examination of these properties. Melt and solid densities for all the feedstocks vary within a similar range of values $\left(1940 \mathrm{~kg} / \mathrm{m}^{3}\right.$ $2580 \mathrm{~kg} / \mathrm{m}^{3}$ ). Melt-specific heats also showed little variation (1040 J/kg K-1410 J/kg K) from filler to filler. Melt thermal conductivity, however, is clearly dominated by the thermal conductivity of the filler and varies widely from system to system $(0.7 \mathrm{~W} / \mathrm{m} \mathrm{K}-2.9 \mathrm{~W} / \mathrm{m} \mathrm{K})$. The transition temperature varies between $52^{\circ} \mathrm{C}$ and $53^{\circ} \mathrm{C}$ for all systems except for the zirconia-toughened mullite feedstock for which the transition temperature, $81^{\circ} \mathrm{C}$, approaches that of the binder system, $\sim 100^{\circ} \mathrm{C}$. This behavior is perhaps explained by the relative similarity between the thermal conductivity behavior of the zirconia-toughened mullite feedstock and the binder system as compared with the other feedstock systems.

Trials were performed to confirm the moldability of the feedstock to shape parts with complex geometries. Test coupons with a series of six $\sim 1$-mm-wide slots were molded (Fig. 7) to evaluate the capability of the feedstock. A complete mold filling was achieved, and the obtained green parts showed no warpage, cracks, or surface defects.

After molding, the green parts were thermally debound and sintered in air. Sintered samples

Table III. Summary of the composition, process conditions, and fracture toughness values of mullitezirconia composites reported from prior studies

\section{Composition}

Mullite-20 vol.\% $\mathrm{Zr}(\mathrm{Ce}) \mathrm{O}_{2}$

$\mathrm{Al}_{2} \mathrm{O}_{3}-48.3$ wt.\%-64.9 wt.\% $\mathrm{ZrO}_{2}$

Mullite-0 vol.\%-20 vol.\% $\mathrm{ZrO}_{2}$

Mullite- 0 vol.\%-32 vol.\% $\mathrm{ZrO}_{2}$

Alumina gel-45 wt.\%-75 wt.\%,

Zircon-15 wt.\%-45 wt.\%,

$\mathrm{CeO}_{2}-1.5$ wt. $\%-4.5$ wt.\%,

$\mathrm{Al}-10$ wt.\%

Mullite-53.5 wt.\%-60 wt.\%,

36 wt.\%-40 wt. $\% \mathrm{ZrO}_{2}$,

0 wt. $\%-10$ wt. $\% \mathrm{Y}_{2} \mathrm{O}_{3}$

Mullite-12.5vol.\%-30 vol. $\% \mathrm{ZrO}_{2}$

Mullite-10 wt. $\% \mathrm{ZrO}_{2}, 1$ wt.\% $\mathrm{MgO}$
Mullite-5 vol.\%-20 vol. $\% \mathrm{ZrO}_{2}$

\begin{tabular}{c} 
Process \\
\hline PIM \\
Slip casting, reaction sintered \\
Attrition milling isostatic \\
pressing \\
Uniaxial pressing \\
Uniaxial pressing \\
Wet interaction, Uniaxial \\
pressing
\end{tabular}

Attrition milling, uniaxial pressing

Uniaxial pressing

Uniaxial pressing, microwave sintered

\begin{tabular}{c} 
Sintering \\
conditions \\
\hline
\end{tabular}

$1500^{\circ} \mathrm{C}, 4 \mathrm{~h}$

$1450-1600^{\circ} \mathrm{C}, 2 \mathrm{~h}$

$1570^{\circ} \mathrm{C}, 2.5 \mathrm{~h}$

$1600^{\circ} \mathrm{C}, 2 \mathrm{~h}$

$1100-1600^{\circ} \mathrm{C}, 8 \mathrm{~h}$

$1400-1600^{\circ} \mathrm{C}, 2 \mathrm{~h}$

$1500-1600^{\circ} \mathrm{C}, 2 \mathrm{~h}$

$3.7-3.9$

$2.4-3.1$

$3.7 \pm 0.4$
Reference

Present study

2.1-3.9

$2.1-3.2$

$1.8-2.9$

$1.7-3.8$

2-4

29
27

28

25

26 $1500^{\circ} \mathrm{C}$

$1595^{\circ} \mathrm{C}, 3 \mathrm{~h}$

1500 a The range of fracture toughness values represents the lower and upper bounds of the mean values measured over a range of compositions and sintering conditions. The error bars reported in the literature are typically $\pm 0.3 \mathrm{MPa} \mathrm{m}{ }^{1 / 2}$. 
exhibited uniform shrinkage of $\sim 16.5 \%$ (see Fig. 7 ), signifying uniform packing density and feedstock homogeneity. The properties of the sintered parts are summarized in Table II.

It can be seen from Table II that a $~ 97 \%$ dense, zirconia-toughened material with a fracture toughness $\left(K_{\mathrm{c}}\right)$ of $4.3 \pm 0.3 \mathrm{MPa} \mathrm{m}{ }^{1 / 2}$ and a Vickers

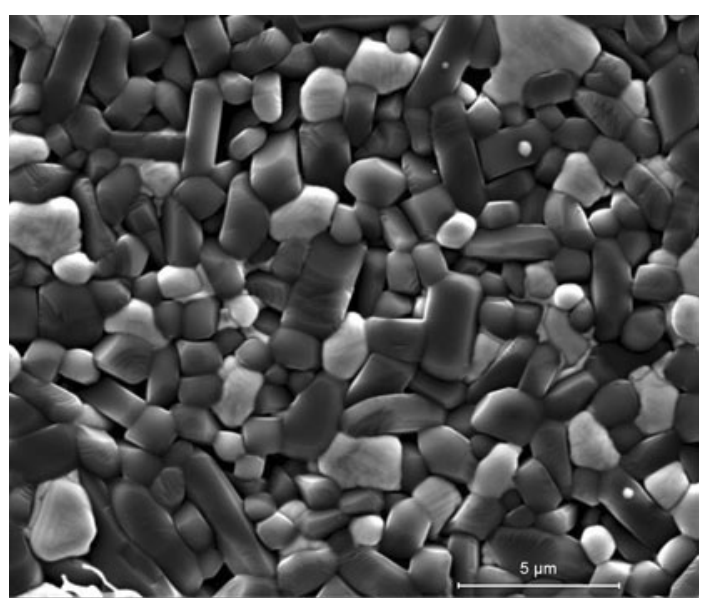

Fig. 8. Scanning electron micrograph for test coupon sintered at $1500^{\circ} \mathrm{C}$ for $4 \mathrm{~h}$. The relatively dark regions represent mullite-rich grains, while the brighter regions represent zirconia-rich grains. The black regions are residual pores. hardness of $11.8 \pm 0.4 \mathrm{GPa}$ was successfully obtained. In contrast, prior studies on mullite and zirconia-toughened mullite typically reported fracture toughness values of $2 \mathrm{MPa} \mathrm{m}^{1 / 2}-4 \mathrm{MPa} \mathrm{m}^{1 / 2}$. The compositions, process conditions, and fracture toughness values of mullite-zirconia composites reported from prior studies are summarized in Table III.

The fracture toughness of the studies listed in Table III was measured using the Vickers indentation method. The fracture toughness values of mullite-zirconia composites for most of the prior studies was less than $4 \mathrm{MPa}$ even after sintering at temperatures above $1500^{\circ} \mathrm{C}$. In the present study, a fracture toughness $\left(K_{\mathrm{c}}\right)$ of $4.3 \pm 0.3 \mathrm{MPa} \mathrm{m}^{1 / 2}$ was achieved at sintering temperatures of $1500^{\circ} \mathrm{C}$. The presence of ceria is likely to contribute to the increase in fracture toughness. The sintered microstructure showed in Fig. 8 reveals dark and light regions corresponding to the mullite and zirconia grains, respectively. The presence of a small amount of residual porosity is also observed in a sintered microstructure. The fracture toughness is likely to be further enhanced as a result of the finer grain size in the mullite and ceria-stabilized zirconia resulting from sintering at the lower temperature of $1500^{\circ} \mathrm{C}$. Metallographic analysis is planned in the future to quantify the grain size of the

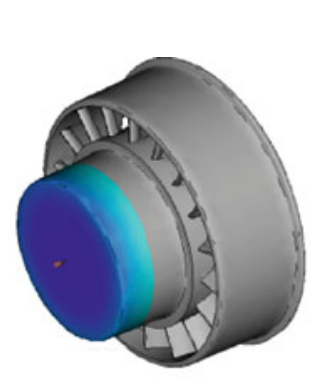

$100 \mathrm{~mm}$

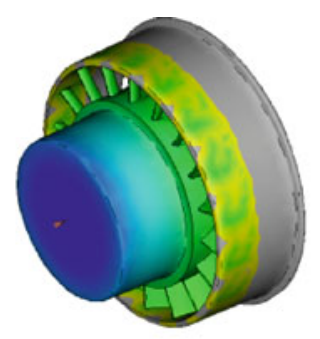

$100 \mathrm{~mm}$

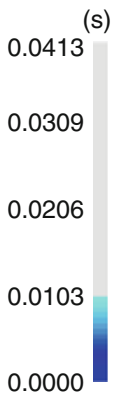

(s)

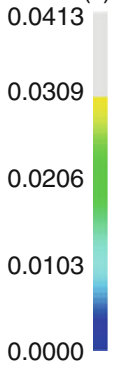

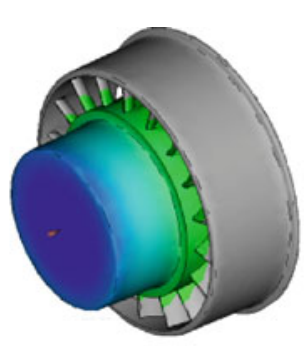

$100 \mathrm{~mm}$

(s)

0.0413

0.0309

0.0206

0.0103

0.0000
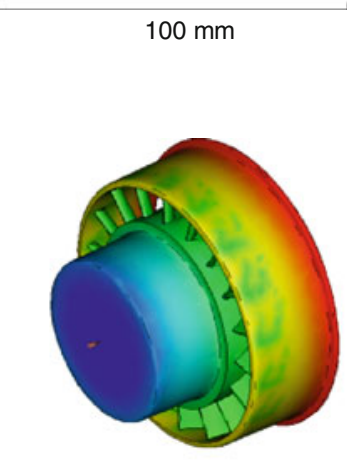

0.0413
0.0309

0.0309
0.0206
0.0103
0.0000

0.0309
0.0206
0.0103
0.0000

0.0309
0.0206
0.0103
0.0000

Fig. 9. Progressive mold filling of zirconia-toughened mullite feedstock for a miniature turbine stator geometry. 
mullite and ceria-stabilized zirconia of the sintered samples.

Preliminary injection simulations were performed to investigate the feasibility of molding a stator component for a miniature turbine. Figure 9 shows the progressive filling of the selected geometry with the zirconia-toughened mullite feedstock. The Moldflow-recommended processing parameters were used for this initial study with a mold temperature of $23^{\circ} \mathrm{C}$ and a melt temperature of $150^{\circ} \mathrm{C}$. With the specified stator geometry, molding was feasible over the entire melt and mold temperature range for the feedstock at fill times below $1.6 \mathrm{~s}$. Although a feasible molding window exists, a preferred molding window was not found for any combination of injection time and melt and mold temperature. Injection pressure and cooling time were set automatically for the analysis, and so adjustment of these parameters will be needed in future studies to determine an optimum window for part quality. The information presented in Table III shows that mullite-zirconia composites are shaped either by tape casting, infiltration method, or uniaxial or isostatic pressing. Unlike PIM, these technologies do not have the capability of fabricating the complex-shaped parts required for high-performance applications. The present study confirms the potential ability of PIM to manufacture complexshaped parts requiring enhanced properties.

\section{CONCLUSIONS}

Zirconia-toughened mullite components sintered to $97 \%$ density and $16.5 \%$ uniform shrinkage were successfully processed by PIM. The feedstock viscosity was less than $10^{3} \mathrm{~Pa}$ s for the range of operating shear rates, indicating that the feedstock is suitable for injection molding. Furthermore, the successful molding of millimeter-scale features indicates that the feedstock is suitable for further investigations to fabricate geometrically complex components. Computer simulations on the moldfilling behavior using experimentally measured rheological and thermal characteristics of the feedstock also supported the potential for fabricating miniature turbine stators for UAVs. The feedstock property measurements were used to understand the mold-filling attributes of ceria-stabilized, zirconia-toughened mullite in the early stages of the design cycle and are reported in the literature for the first time to our knowledge. The fracture toughness $\left(K_{\mathrm{c}}\right)$ of the sintered zirconia-toughened mullite specimens $\left(4.3 \pm 0.3 \mathrm{MPa} \mathrm{m}^{1 / 2}\right)$ fabricated by PIM in this study was higher than that previously reported in the literature on simple geometries fabricated by uniaxial or isostatic pressing. The combined enhancement in sintered attributes and shape complexity of PIM observed in the present study increases the number of potential applications for zirconia-toughened mullite composites such as in the case of miniature turbine stators for unmanned aviation vehicles.

\section{REFERENCES}

1. J. Lenz, R.K. Enneti, V.P. Onbattuvelli, K.H. Kate, R. Martin, and S. Atre, JOM 388-392 (2012).

2. R. Kamo and W. Bryzik, SAE Paper 790645, 1979.

3. R.R. Sekar, R. Kamo, and J.C. Wood, SAE Paper 840834, 1984.

4. V.P. Onbattuvelli, R.K. Enneti, S.J. Park, and S.V. Atre, Int. J. Refract. Met. Hard Mater. 36, 77 (2013).

5. K.H. Kate, V.P. Onbattuvelli, R.K. Enneti, S.W. Lee, S.J. Park, and S.V. Atre, JOM 64, 1048 (2012).

6. V.P. Onbattuvelli, S. Vallury, T. McCabe, S.J. Park, and S.V. Atre, Powder Inj. Mould. Int. 4, 64 (2010).

7. K.H. Kate, R.K. Enneti, V.P. Onbattuvelli, and S.V. Atre, Ceram. Int. 38, 6495 (2013).

8. V.P. Onbattuvelli, R.K. Enneti, and S.V. Atre, Ceram. Int. 38, 6495 (2012).

9. R.K. Enneti, S.J. Park, A. Schenck, R.M. German, P. Thomas, B. Levenfeld, A. Várez, I.O. Palagi de Souza, J.P. de Souza, A.M. Fuentefria, V.P. Onbattuvelli, and S.V. Atre, Int. J. Powder Metall. 48, 23 (2012).

10. R.M. German, Int. J. Powder Metall. 36, 31 (2000).

11. G. Aggarwal, S.J. Park, and I. Smid, Int. J. Refract. Met. Hard Mater. 24, 253 (2006).

12. D.F. Heaney, Handbook of Metal Injection Molding (Cambridge: Woodhead Publishing Limited, 2012).

13. B.A. Bender and M.J. Pan, Mechanical Properties and Performance of Engineering Ceramics and Composites IV-33rd. International Conference on Advanced Ceramics and Composites, vol. 30, 2010, pp. 167-75.

14. K. Okada, N. Otsuka, R.J. Brook, and A.J. Moulson, J. Am. Ceram. Soc. 72, 2369 (1989).

15. M. Imose, A. Ohta, Y. Takano, M. Yoshinaka, K. Hirota, and O. Yamaguchi, J. Am. Ceram. Soc. 1050 (1998).

16. M.J. Vick, A. Heyes, and K. Pullen, J. Eng. Gas Turbines Power 132, 092301 (2010).

19. L. Kowalski and J. Duszczyk, J. Mater. Sci. 18, 1417 (1999).

20. C. Nylund and K. Meinander, Heat Mass Transfer 41, 428 (2005).

21. J. Shah and R.E. Nunn, Powder Metall. Int. 19, 38 (1987).

22. L. Liu, N.H. Loh, B.Y. Tay, S.B. Tor, Y. Murakoshi, and R. Maeda, Mater. Charact. 54, 230 (2005).

17. V.P. Onbattuvelli, (Ph.D Dissertation, Oregon State University, 2010).

18. L. Kowalski, J. Duszczyk, and L. Katgerman, J. Mater. Sci. 34, 1 (1999).

23. S.Laddha, (Ph.D Dissertation, Oregon State University, 2008).

24. L.B. Garrido, E.F. Aglietti, L. Martorello, M.A. Camerucci, and A.L. Cavalieri, Mater. Sci. Eng. A 419, 290 (2006).

25. J.S. Moya and M.I. Osendi, J. Mater. Sci. 19, 2909 (1984).

26. F. Sahnoune, N. Saheb, and P. Goeuriot, Adv. Mater. Res. 160-162, 1772 (2010).

27. J. Shyu and Y. Chen, J. Mater. Res. 10, 63 (1995).

28. S. Maitra, R. Chatterjee, S. Das, and A. Rahaman, J Aust. Ceram. Soc. 42, 71 (2006).

29. M.K. Haldar, T.K. Pal, and G. Banerjee, Ceram. Int. 28, 311 (2002).

30. J. Moran, T. Kelly, S. McKenna Lawlor, and J.A. Slevin, Key Eng. Mater. 32, 57 (1991).

31. S. Bodhak, S. Bose, and A. Bandyopadhyay, J. Am. Ceram. Soc. 94, 32 (2011).

32. D.M. Bigg and R.G. Barry, Proceedings of the 1998 56th Annual Technical Conference, vol. 1, 1998, pp. 997-1000. 